\title{
O TRANSUMANISMO E O PÓS-HUMANISMO: UMA VISÃO DOS DIREITOS HUMANOS À LUZ DA EVOLUÇÃO TECNOLÓGICA E DA SUSTENTABILIDADE
}

\author{
Ricardo Fabel Braga ${ }^{1}$ \\ Luciana Machado Teixeira Fabel ${ }^{2}$
}

\section{RESUMO}

O desenvolvimento tecnológico vem trazendo mudanças significativas na condição humana. $\mathrm{O}$ aprimoramento e aplicação de novas tecnologias em sistemas biológicos e organismos vivos tem impulsionado cada vez mais a biotecnologia. Nesse contexto surge o Transumanismo como uma perspectiva de melhoria na condição humana. Este artigo tem o objetivo de analisar o Transumanismo e o Pós-humanismo sob a ótica das evoluções biotecnológicas e da sustentabilidade. A evolução tecnológica deve ser analisada sob a visão da equidade intergeracional e da valorização das condições humanas. Esta pesquisa possui um delineamento qualitativo, através de pesquisa bibliográfica exploratória e explicativa, fazendo uso do método hipotético-dedutivo.

PALAVRAS-CHAVE: Direitos Humanos. Evolução Tecnológica. Pós-humanismo. Sustentabilidade. Transumanismo.

\section{TRANSHUMANISM AND POSTHUMANISM: A VISION OF HUMAN RIGHTS IN THE LIGHT OF TECHNOLOGICAL EVOLUTION AND SUSTAINABILITY}

\begin{abstract}
Technological development has brought significant changes to the human condition. The improvement and application of new technologies in biological systems and living organisms has increasingly driven biotechnology. In this context, Transhumanism emerges as a perspective for improving the human condition. This article aims to analyze Transhumanism and Post-humanism from the perspective of biotechnological evolutions and sustainability. Technological evolution must be analyzed from the perspective of intergenerational equity and the valorization of human conditions. This research has a qualitative design, through exploratory and explanatory bibliographic research, using the hypothetical-deductive method.
\end{abstract} KEYWORDS: Human rights. Posthumanism. Sustainability. Technological Evolution. Transhumanism.

\section{INTRODUÇÃO}

\footnotetext{
${ }^{1}$ Mestrando em Direito Ambiental e Desenvolvimento Sustentável pela Dom Helder Escola de Direito, PósGraduações em Administração Financeira e Desenvolvimento Gerencial, ambas pela Fundação Dom Cabral, Engenheiro Eletricista pela PUC-MG. http://lattes.cnpq.br/924430240457519; ORCID:https://orcid.org/00000001-9169-309; ricardo.fabel@ hotmail.com.

2 Doutoranda em Direito Ambiental e Desenvolvimento Sustentável Escola Superior Dom Helder Câmara. Mestre Administração e Especialista em Direito Público, Governança, Riscos e Compliance. Advogada. Professora. Lattes: http://lattes.cnpq.br/0066168370629118; ORCID: https://orcid.org/0000-0001-57489757;lucianamt@bol.com.br.
} 
A evolução tecnológica e a sua consequente utilização para a melhoria da qualidade de vida, e, por vezes até a própria evolução humana, vem percorrendo a história. Muitas evoluções têm levado alterações na forma de trabalho, comportamentos sociais e culturais. Em 600 a.C, Tales de Mileto inventou a eletricidade estática. No século XVIII surge a revolução industrial, com a utilização massiva de máquinas. Em 1879 Thomas Edison inventou a lâmpada elétrica incandescente A descoberta da radioatividade no urânio, pelo francês Henri Becquerel, em 1896 quando a polonesa Marie Curie e seu marido, o francês Pierre Curie, descobriram vários elementos químicos radioativos (rádio, o polônio e o tório), demonstrando que a radioatividade não era apenas o urânio. Em 1987 a internet foi liberada para uso comercial nos Estados Unidos. Esses casos retromencionados demonstram que o processo tecnológico acompanha a evolução da humanidade e seu retrocesso é descabido e inviável.

As evoluções tecnológicas trazem benefícios, mas também carregam males, como as alterações climáticas, o aumento de resíduos sólidos, desastres ambientais amparados pelo progressivo esgotamento de recursos naturais finitos. As sociedades de classes passam a ser sociedades de risco. Catástrofes ambientais provenientes de mudanças climáticas como o furacão Katrina nos Estados Unidos, escancaram que não se trata apenas de uma mudança climática, mas uma mudança de características, como hábitos de consumo, da tecnologia, do crescimento da população, cultura e política. As catástrofes nucleares de Chernobyl e Fukushima evidenciam que apesar da energia nuclear trazer muitos benefícios tecnológicos para a sociedade traz também os males pelos riscos da radioatividade. As usinas Hidrelétricas com efeitos significativos em termos de geração de energia liberam gases de efeito estufa na atmosfera. A mineração de relevante e indubitável importância para a sociedade possuindo nas suas commodities a base para a evolução tecnológica, demonstra seus malefícios pelos significantes impactos ambientais e sociais.

Apesar das grandes variações que apresentamos como indivíduos e pertencentes a uma determinada cultura, partilhamos de valores comuns, cuja essência caracteriza a humanidade que nos confere a possibilidade de comunicar e estabelecer valores morais, éticos e de direitos aos comportamentos, objetivando uma regra de conduta em relação ao próximo e com o planeta que coabitamos.

O reconhecimento do direito ao meio ambiente ecologicamente equilibrado, como fundamental, conforme proposto por Convenções Internacionais, sobremaneira a partir de 1962 e, internamente, disposto pela Constituição da República Federativa do Brasil de 1988, 
figura-se entre esses valores e direitos, constituindo-se aspecto central da sociedade contemporânea.

Dentre os objetivos propostos, tem-se o direito ao meio ambiente, disposto como uma obrigação para as gerações futuras, o que representa, simultaneamente, a essência da matéria ambiental e sua maior instabilidade como objeto de direito, considerando-se os aspectos futuros, cuja previsão não comporta regulação normativa segura, quer seja pela imprecisão de conexões entre fatores humanos e sua relação com o meio ambiente.

A evolução tecnológica nessa trilha, encontra-se na era do Transumanismo e Póshumanismo. É necessário avaliar e elucidar as implicações dessas tecnologias. Em uma inferência de direito e futuro, a tecnologia tem influenciado a manutenção, modificação e extinção das espécies, numa clara concepção de que se pode modificar espécies benéficas, bem como extinguir espécies maléficas. A problemática das garantias e a imprevisibilidade das mudanças comportamentais humanas e suas aspirações no cenário de preservar aquilo que partilhamos como valores comuns, ainda que não emanados de normas, deve se lastrear na sustentabilidade e no bem comum. A interação entre humanos e a intervenção tecnocientífica nos variados usos, deve proporcionar um desenvolvimento sustentável e a preservação dos direitos humanos.

Na conceituação do Transumanismo, tem-se a expressão da interação entre humanos e a intervenção tecnocientífica nos mais variados usos, sendo relevante analisar seus impactos nos direitos humanos e no meio ambiente, por afetar diretamente a perpetuação e preservação dos seres humanos e não humanos. É importante identificar novas maneiras de conceituar o mundo atual em que vivemos. As transformações necessárias são ao mesmo tempo cientificas, filosóficas e jurídicas.

Analisar esse novo cenário sob a perspectiva dos desafios que trazem para a questão ambiental e as aspirações humanas decorrentes, buscando um equilíbrio entre o direito ambiental e o Transumanismo como uma teoria que busca agregar valores para além da norma positivada.

É preciso compreender o direito além daquilo que se encontra associado à norma jurídica, cujo dever ser é capaz de vincular pessoas às obrigações de conduta previamente impostas, conjugando-se com instrumentos de efetividade na prestação dos direitos e na equalização dos valores aptos a manter a ordem social. Analisando as normas jurídicas, observa-se que o meio ambiente é disposto como garantia a ser preservada com foco na 
equidade intergeracional, É imperativo ponderar acerca da efetividade dessas normas e aqui, propõe-se somar essas questões às mudanças propostas pelo Transumanismo.

É sobre esse enfoque que o tema problema da pesquisa se desenvolve, a partir da análise conceitual do meio ambiente e do Transumanismo para encontrar elementos dedutivos de modo que a preservação ambiental seja direito fundamental também sob a ótica transumanista. Como hipótese busca-se a constatação de que a preservação dos bens ambientais é a forma mais segura de garantir inclusive, que o Transumanismo não impacte de forma negativa as formas de vidas existentes.

Essa pesquisa possui um delineamento qualitativo através de pesquisa bibliográfica exploratória e explicativa, fazendo uso do método hipotético-dedutivo. $\mathrm{O}$ artigo está dividido em Capítulo 1 -Introdução, Discussão do tema nos Capítulos 2 e 3. Considerações Gerais no Capítulo 4 . O Capítulo 2 traz a questão das gerações futuras e o reconhecimento do direito fundamental ao meio ambiente ecologicamente equilibrado. O capítulo 3 estabelece o debate acerca do Transumanismo e o Pós-humanismo no tocante às oportunidades e ameaças para o ser humano e o planeta. No capítulo 4 as considerações finais e conclusões em relação à pesquisa realizada.

\section{AS GERAÇÕES FUTURAS E O DIREITO AO MEIO AMBIENTE ECOLOGICAMENTE EQUILIBRADO: A PERCEPÇÃO DA DIGNIDADE HUMANA}

Em uma premissa democrática, mesmo quando representada em processo autocompositivo pelo qual a identidade presumidamente homogênea de uma comunidade se realiza, deverá observar os mecanismos de efetivação de modo a evitar que seja concebida e regulada mecanicamente por regras que legitimam a escolha por interesses daqueles que supostamente representa.

O acesso ao processo de formação normativa de forma livre e desvinculada dos interesses pontuais pressupõe, também, o constante discernir dos interesses públicos e privados, pautando-se pelo reconhecimento dos direitos fundamentais e da abertura constitucional à interpretação jurídica a esta vinculada.

Nesse sentido, a busca da efetividade da Constituição - rito de passagem para o início da maturidade institucional brasileira - tornou-se uma ideia vitoriosa e incontestada. As normas constitucionais conquistaram o status pleno de normas jurídicas, dotadas de 
imperatividade, aptas a tutelar direta e imediatamente todas as situações que contemplam. Mais do que isso, a Constituição passa a ser a lente através da qual se leêm e se interpretam todas as normas infraconstitucionais, bem como a atuação de cada um dos poderes e instituições no exercício de suas respectivas funções.

Assegurar a real efetividade dos direitos firmados sem permitir que se transforme em compromisso de atendimento a interesses pontuais é um desafio posto. Nesse sentido, é necessário, embora não sendo suficientemente resolutivo, perseguir os requisitos intrínsecos a que deve uma norma jurídica obedecer para que seja considerada válida, sobretudo na vasta prática de poder regulamentar em matéria ambiental.

A previsão de um direito no ordenamento constitucional certamente representa um importante instrumento normativo de viabilidade para sua execução, o que segundo Silva (1994), a Declaração de Estocolmo abriu caminho para que as constituições supervenientes reconhecessem o meio ambiente ecologicamente equilibrado como um direito fundamental entre os direitos sociais, na perspectiva de "direitos a serem realizados", sem desconsiderar outros importantes dispositivos em que os valores ambientais se apresentam sob o véu de outros objetos de normatividade constitucional.

Tem-se no contexto constitucional brasileiro elementos como soberania cidadã para defender e proteger o meio ambiente, a defesa do ecossistema como um dos princípios da ordem econômica, e a disposição adequada por meio dos mecanismos de governo para assegurar o acesso ao bem ambiental.

A existência de uma constituição pressupõe que: "a norma constitucional existe para ser aplicada" (MACHADO, 2004, p.21). No plano da interpretação das normas constitucionais, fazem repercutir os ensinamentos da doutrina alemã - sobremaneira nas figuras de Konrad Hesse e Friedrich Müller - trazendo argumentos relevantes para a busca da concretização do princípio da máxima efetividade, do princípio da interpretação efetiva, ou, ainda, do princípio da eficiência. O grande desafio dos constitucionalistas é, dentro das técnicas de interpretação, atribuir à norma constitucional o sentido que maior efetividade lhe dê. (CANOTILHO, 2001, p. 1141-5).

O estudo da eficácia da normativa é relevante pressuposto com objetivo de tornar concreto o desejo do legislador constituinte, ao consagrar diretivas de cumprimento por parte do ente estatal. 
O status constitucional da questão ambiental revela uma nova perspectiva sobre o meio ambiente e a ordem econômica dependente dos recursos naturais, pois possibilita que os princípios e regras gerais ali reconhecidos sejam tomados como direcionamento, bem como para a efetivação dos direitos e a concretização de um propósito igualmente comum.

As normas de direitos fundamentais são autoaplicáveis de regra, objetivando, efetivamente, a fruição dos direitos constitucionais por todos aqueles que assim desejassem, desde que estivessem enquadrados, abstratamente, na hipótese normativa consagrada. Machado (2004, p. 22) ressalta que se deve "penetrar no nebuloso espaço da aplicabilidade das normas constitucionais". Na linguagem jurídica, por isso, aplicar a norma vai significar pô-la em contato com um referente objetivo (fatos e atos). A aplicabilidade, assim, exige interpretação, condições de possibilidade que no direito estão referidas a aspectos técnicos inerentes à estrutura das normas e da realidade. Na teoria jurídica, estas condições reportamse à noção de eficácia. Sobre eficácia, em breve síntese, pode-se afirmar que é a possibilidade de estar a norma apta a ser aplicada, por reunir todos os elementos e meios necessários à sua operatividade.

Nesses termos, partindo da noção de aplicabilidade, conjugada com o conceito de eficácia, bem como da disposição constitucional de direito ao meio ambiente e o Estado como seu garantidor, questiona-se a eficácia dos instrumentos nesse propósito. É relevante observar que esses direitos estão intimamente relacionados a ação estatal e suas diversas expressões bem como suas fragilidades expostas em razão de sua insuficiência, característica do estado contemporâneo.

Isso significa que não é suficiente o seu reconhecimento como garantia políticaglobal, exigindo-se a capacidade de resultado e a eficácia jurídica e a efetividade prática.

De acordo com Morais, numa referência à Ferrajoli, “A crise institucional corresponde ao ato de desconstitucionalização, que se alega ser promovido pelo neoliberalismo", que se instaura "pela ausência de uma verdadeira esfera pública, autônoma e supra ordenada à esfera privada". (MORAIS, 2017, p. 21 e 22). Assim, essa dissonância reflete um abismo entre a previsão constitucional e o que de fato se tem garantido.

A disposição constitucional de algumas matérias é de relevância ímpar na efetivação do que ali se propõe. Contudo, requer uma constante avaliação do que necessita ser interpretado e aplicado. 
Na exposição de Sampaio (2001), tem-se um conjunto de elementos necessários à estabilização do disposto constitucional.

O consenso constitucional é o estágio primeiro de criação e estabilização do consenso sobreposto. Ele se firma na institucionalização de certos princípios de justiça e de procedimentos eleitorais democráticos aceitos como um modus vivendi $\mathrm{e}$ destinados a "moderar a rivalidade política no interior da sociedade": "O consenso constitucional não é profundo e tampouco é amplo: seu âmbito é restrito, não inclui a estrutura básica, mas apenas os procedimentos políticos do governo democrático" (p. 206). Põem-se como requisitos da estabilidade desse consenso: a) a garantia e a prioridade especial dos direitos políticos fundamentais (voto, expressão, associação), associadas a medidas que se destinam a assegurar aos cidadãos meios materiais para o gozo de tais direitos, retirando da agenda política discussões e cálculos dos interesses sociais sobre referidas questões; b) o uso público da razão pública na aplicação dos princípios liberais de justiça; e c) o reconhecimento pelos cidadãos de que as instituições políticas básicas incorporam esses princípios e a forma de razão pública empregada, de modo a estimular as "virtudes da cooperação política que tornam possível um regime constitucional", integrantes do "capital político da sociedade", como a tolerância, a disposição de fazer concessões mútuas, a razoabilidade e o senso de justiça. (SAMPAIO, 2001, p.770).

No contexto empírico normativo em matéria ambiental, a mera descrição de comportamentos e proibições não comunga com a real prioridade estabelecida pela sociedade, seja ela de forma proativa ou simplesmente pela ausência de participação nas ações de efetivação do direito à estabilidade ecológica como condição da vida humana e dos demais seres.

Dentro da perspectiva do Estado não lhe cabe se furtar à análise dos problemas e desafios gerados pela degradação ambiental para as gerações presentes e futuras. Cabendo ao Direito, portanto, a fim de restabelecer o equilibro e a segurança nas relações socioambientais, a missão de posicionar-se em relação a essas novas ameaças que fragilizam e colocam em risco a ordem de valores e os princípios republicanos e do Estado Democrático de Direito, bem como comprometem fortemente a sobrevivência humana e não humana e qualidade de vida. (SARLET E FENSTERSEIFER, 2013, p.44).

Cumpre ao Estado o reconhecimento do direito fundamental ao meio ambiente ecologicamente equilibrado consoante o artigo 225 da CRFB, no sentido da inscrição de uma Teoria Constitucional e de Direitos Fundamentais "ecologicamente adequada e comprometida”. (SARLET E FENSTERSEIFER, 2013).

O direito ambiental passa a ser reconhecido como direito fundamental ligado a dignidade humana sendo que a principal destinatária da norma constitucional, em face de suas inter-relações com o meio ambiente é a pessoa humana. 
Além disso, ao fazer menção ao direito ambiental das "gerações atuais e futuras" a CRFB em seu artigo 225 apontou a necessidade de assegurar a tutela jurídica do meio ambiente em decorrência da extensão de tempo médio, entre o nascimento de uma pessoa humana e o nascimento de seu descendente (FIORILLO, 2010). Portanto, compete a Constituição na esfera jurídica material tutelar "um direito ambiental a partir do patrimônio genético, observando, no plano jurídico processual, um critério preventivo como único meio de garantir um direito ambiental efetivamente direcionado às gerações futuras" (FIORILLO, 2010, p. 35).

$\mathrm{Na}$ seara ambiental, a perpetuação da espécie humana está diretamente ligada a "ideia de responsabilidade e dever jurídico (para além do plano moral) para com as gerações futuras" (SARLET E FENSTERSEIFER, 2013).

O filósofo do direito Ost (1999), esboça a sua preocupação na construção de pontes existenciais entre as gerações humanas, utilizando a questão ambiental como o paradigma mais evidente do que ele denomina de "risco de discronia". Para o autor, a proteção do ambiente revela uma situação de "destemporalização", na medida em que se está a admitir que o comportamento dos seres humanos contemporâneos como por exemplo, nos modos de produção e consumo, repercute de forma direta nas condições existenciais das futuras gerações, com a degradação e poluição ambiental aumentando de forma cumulativa para o futuro. (OST, 1999, p.39-41).

O que se evidencia é a dimensão temporal das questões ambientais, visto que a degradação ou preservação ambiental é também matéria de direito de gerações vindouras. Por isso, o maior desafio está em conciliar o desenvolvimento econômico com a preservação ambiental para as gerações futuras e atuais. Portanto o "direito do consumo e o direito do meio ambiente construíram-se pouco a pouco como direitos quase "antieconômicos" porque apareceram como fundados sobre princípios contrários ao direito e a economia liberais". (FARJAT apud THOMÉ, 2014, p. 46).

Entretanto, a utilização e uso dos bens naturais é algo inevitável, sendo necessário hodiernamente, "na sociedade de risco, e a partir da constitucionalização da proteção ambiental, tem-se a plena convicção de que o Estado deve atuar no domínio econômico com o intuito de, dentre outros objetivos, implementar o desenvolvimento sustentável". (THOMÉ, 2014, p. 46). 
No âmbito do Estado Socioambiental de Direito, a responsabilidade não é só estatal, mesmo porque "a partir da sua dimensão intergeracional, o princípio da solidariedade aponta para um complexo de responsabilidades e deveres das gerações contemporâneas "viventes" em resguardar as condições existenciais para as pessoas que virão a habitar o planeta”. (SARLET E FENSTERSEIFER, 2013).

O reconhecimento da dignidade das futuras gerações humanas, assim como da dignidade dos não humanos e da natureza em si, surge como mais um elemento a formatar e ampliar o conhecimento e o alcance da proteção e reconhecimento pelo direito da percepção da dignidade humana, característica da tradição ocidental, especialmente desde Kant, e que nos tem servido como guia até o atual estágio do pensamento humano. (SARLET E FENSTERSEIFER, 2013, p. 52).

Sobre dignidade humana ainda se destaca a importância de associá-la à ética, conforme exposto por Barreto: "Falar da dignidade humana sem que se situe esta idéia no quadro de uma ética e antropologia filosófica determinada resulta lançar o valor que ela representa no vazio dos discursos políticos e jurídicos.” (BARRETO, 2003, p. 219).

Associar desenvolvimento sustentável com dignidade humana é de suma importância para o alcance dos objetivos propostos tanto pelo Transumanismo como pelo direito ambiental.

Enfatizando esses aspectos, Brito (2016), destaca que:

\footnotetext{
A razão que move a existência humana é comumente envolvida por utopias que estimulam a potência do agir, o desejo de transpor as contradições do existir, para que a motivação última de se alcançar o status da dignidade se perfile ao ideal supremo da realização. A este fim muitas narrativas teóricas são forjadas - cada qual a buscar dentro de seu ideário a matriz de legitimação no sistema de governo das vidas humanas. ( BRITO, 2016, p.18).
}

O desenvolvimento sustentável não foi totalmente adotado por nenhum dos lados no debate sobre crescimento e conservação. $\mathrm{O}$ receio de que as gerações atuais e futuras não consigam manter seus padrões de vida, estimulou um modo de pensar que informaria discursos que preparavam o caminho para o surgimento e adoção global de comportamento, restando identificar qual conduta predominante.

O debate acerca do desenvolvimento sustentável vem evoluindo em um processo de aprendizado da sociedade, porém acompanhado por um processo vertiginoso de evolução tecnológica com a perspectiva do Transumanismo e do Pós-humanismo, onde a busca pela 
transcendência da condição humana e no prolongamento da existência se tornaram o propósito. Esse desenvolvimento tecnológico pode trazer a percepção de prosperidade e por outo lado produzir desigualdades sociais e danos ao meio ambiente.

\section{O TRANSUMANISMO E O PÓS-HUMANISMO: AS OPORTUNIDADES E AMEAÇAS}

O Transumanismo é um movimento cultural e ideológico que se iniciou a muitos anos em meados dos anos 50. O termo Transumanismo foi criado pelo biólogo britânico Julian Huxley, irmão do escritor Aldous Huxley, em 1957. Huxley definia esse conceito como "homem continuando homem, mas transcendendo, ao perceber novas possibilidades de e para sua natureza humana".

O Transumanismo gradativamente veio evoluindo até que nas últimas duas décadas apresentou os ganhos das evoluções tecnológicas. Tem como premissa a melhora da condição humana através do uso de tecnologias. Essa evolução do ser humano, pautada em princípios éticos e morais, busca aumentar a capacidade intelectual e física do homem, como forma de prolongar a vida, erradicando doenças e potencializando aptidões.

O Canaltech (2015), site especializado em tecnologias, traz uma contribuição de Santos: "os ideais transumanistas se fundamentam, basicamente, em dois pilares. O primeiro deles seria o combate ao envelhecimento e, em consequência disso, a morte; o segundo, é o que trata a simbiose entre orgânico e cibernético como o próximo passo da evolução humana.”(CANALTECH, 2015).

Assim, verifica-se que a raça humana agora é capaz de modificar o próprio corpo humano, tendo a tecnologia como um indutor ao invés da seleção natural. A manipulação genética em um primeiro momento e, mais recentemente, o uso de implantes mecânicos capazes de transformar seres humanos em um misto de cibernético e humano denominados ciborgues.

As lições aprendidas com a evolução tecnológica da história trazem à tona que toda invenção traz consigo os bens e por outro lado os males. Destarte, o os avanços do Transumanismo devem ser avaliados para que se permita entender com todo critério que qualquer decisão tecnológica implicará em uma série de responsabilidades com as gerações 
presentes e futuras, sendo inevitável não escapar de impactos ainda desconhecidos ao meio ambiente.

De acordo com a compreensão de Keoma (2018), o Transumanismo é uma "renovação contemporânea do humanismo", na medida em que abrange e, eventualmente, amplifica os aspectos centrais do pensamento humanista secular e iluminista, como crença na razão, individualismo, ciência, progresso, bem como auto perfeição ou cultivo.

A corrente de pensamento Transumanista ganhou força na segunda metade do século XXI, cuja associação está relacionada aos grandes avanços tecnológicos e da humanidade na relação íntima com as tecnologias e técnicas aplicadas aos humanos, sejam em tratamento de saúde ou na simples intervenção em busca de melhor qualidade de vida e melhoramento de desempenho físico, fisiológico e psíquico. (PORTER, 2017).

A interação entre humano e as possibilidades criadas a partir de novas tecnologias foram instrumentos presentes em ficções científicas, cuja narrativa está centrada nas possibilidades de que a tecnologia pode servir ao homem em suas infinitas possibilidades. Porter (2017), lembra que as hipóteses apresentadas pelo Transumanismo derivam da filosofia futurista que empresta realidade e ficção em um mesmo contexto no movimento de extropia ${ }^{3}$.

Nessa perspectiva de ficção cientifica o clássico filme Blade Runner - O Caçador de Androides, um emblemático filme de ficção cientifica dos anos 80, traz um posicionamento espaço-temporal, substituindo o natural pelo artificial onde se evidencia questões sociais e ambientais como desumanização do planeta, impactos ambientais, efeitos climáticos e diferenças sociais. No que tange ao contexto filosófico é importante destacar a celebre frase do personagem de um humano em relação a um androide, com aspecto idêntico ao dos humanos, denominado replicante: "que ele queria eram as mesmas respostas que todos nós queremos. De onde vim? Para onde vou? Quanto tempo eu tenho?”

Nessa visão, Rüdiger (2017), enfatiza que:

\footnotetext{
${ }^{3}$ Em 1988, Max More e Tom Bell começaram com algumas dezenas de exemplares a publicação da Extropian Magazine, embrião do instituto do mesmo nome, fundado em 1991. A proposta dos visionários era desenvolver estudos e promover ações contra a entropia que, crêem, ameaça a humanidade. O passo seguinte foi criar uma lista de discussão via internet, que se tornou cult e começou a projetar o grupo entre os partidários da tecnocracia vanguardista. Quando promoveram o seminário Extro I (Sunnyvale, CA, 1994), o número de simpatizantes já era uns poucos milhares, mas entre eles havia gente de prestígio, como os já mencionados Hans Moravec, Marvin Minsky e Eric Drexler. O Instituto Extropiano apresentou-se ao público como um laboratório de ideias a respeito das mudanças produzidas pelo desenvolvimento tecnológico. Durante seu breve período de vida, propôs-se, em essências, a reunir pessoas intelectualmente privilegiadas para pensar o futuro humano em sentido radical. $\mathrm{O}$ fundamento em transformação desse trabalho seria uma filosofia transumanista, a filosofia da extropia.(RÜDIGER,2017. p.10)
} 


\begin{abstract}
Durante séculos, o homem teve de se submeter aos mais variados tipos de rituais, que inscreviam em seu corpo as marcas e obrigações prescritas pela ordem coletiva. Agora parece estar se esboçando em nosso horizonte o aparecimento de um indivíduo experimental, conforme o qual nossa identidade cultural e biológica se predispõe à intervenção tecnológica e maquinística. A condução da vida se pauta por princípios tecnológicos, depois de ter se guiado por normas religiosas, políticas e morais. Somos cada vez mais inclinados a fazer transplante de órgãos, cirurgias plásticas, fortalecer a saúde, prevenir doenças, consumir drogas etc. que apontam para um devir ciborgue. (RÜDIGER,2017. p.14)
\end{abstract}

A questão que se verifica na atualidade é que o problema não consiste mais em ser pós-humano, porque essa mudança já se encontra em progresso. O que é necessário avaliar é como será a pós-humanidade e quais a ameaças para a dignidade humana e para o meio ambiente.

Para Maia (2017), a tecnociência e o movimento transumanista permanece como elemento fictício e ameaça aumentar os hiatos entre as diferentes populações e consequentemente, a relação com o meio ambiente e o que se propõe como sustentabilidade:

\footnotetext{
Dentro daquilo que tem sido o processo histórico decorrido desde o colonialismo europeu e posteriormente com a revolução industrial, com um modelo econômico-financeiro de base capitalista, as estatísticas apresentadas demonstram que se têm gerado grandes assimetrias, a vários níveis, entre o Norte e o Sul globais. Está precisamente em causa o reconhecimento da espécie, no seu conjunto, à sua humanidade num contexto em que ocorrem graves atentados em relação ao património cultural e natural. (MAIA, 2017, p.7).
}

As tecnologias reivindicadas pelos transumanistas para os seus propósitos constituem de fato uma fonte enorme que pode ser utilizada para os mais variados fins. Embora haja céticos em relação à possibilidade de se conseguir, do ponto de vista técnico, alguns desses avanços tecnológicos, também há quem, não duvidando da sua exequibilidade, se opõe ao uso de determinados processos temendo as consequências que isso poderá ter para a espécie humana, para a sociedade e para o próprio planeta. Aliás, nas aplicações que essas tecnologias já possibilitam atualmente, já é possível observar situações que são bastante questionáveis do ponto de vista ético-moral. (MAIA, 2017).

As evoluções tecnológicas desenfreadas trazem benefícios incontáveis para a sociedade moderna, mas em contrapartida na perspectiva intergeracional podem se constituir em grandes ameaças para as gerações vindouras com riscos ainda desconhecidos. 
O uso indiscriminado das tecnologias como forma de melhorar o desempenho das espécies foi abordado em alguns países, merecendo destaque a legislação da Suíça que restringe o seu uso, conforme exposto por Sampaio:

Suíça ainda merece um destaque pela restrição ao uso de tecnologia genética não humana. A Confederação deve disciplinar o uso de material reprodutivo e genético de animais, plantas e outros organismos. Ao fazê-lo, deve ter em conta a "dignidade dos seres vivos, bem como a segurança dos seres humanos, dos animais e do ambiente, e deve proteger a diversidade genética das espécies animais e vegetais. (SAMPAIO, 2016, p. 93).

Para Keoma (2018), as pretensões científicas são uma tentativa de comungar mitologias e o que se desenvolveu no mundo das tecnologias, a mistura do humano e do "divino" no contexto daquilo que cria a partir da razão e do conhecimento.

\footnotetext{
Noutras palavras, esta espécie de síndrome de "ruminação" impele o desenvolvimento da ciência no sentido de uma atualização dos mitos. A ciência moderna é mais uma técnica da imaginação para trazer para dentro da realidade a operação do intelecto mágico e a mitologia da antiguidade, com consistência e regularidade previsível. Isto implica, elucidam os autores, que o "intelecto mágico encontrado tão frequentemente em textos antigos, mitos e monumentos é, de fato, o produto de uma ciência em decadência, mas ciência apesar de tudo." Muito da física moderna pode ser vista somente como uma metafísica hermética com equações topológicas, e por um processo análogo de examinação, muito da genética moderna pode ser Transumanismo e suas oscilações. (KEOMA, 2018, p. 221).
}

Tais tecnologias poderão, no limite, "alterar a nossa ontogênese" enquanto espécie, principalmente se atendermos ao fato de cada vez mais se falar no desenvolvimento da clonagem reprodutiva e na possibilidade de uma hibridização entre o humano e a máquina. Tais fenômenos arriscam-se a não estar desligados de um contexto socioeconômico e sociocultural que hoje em dia reproduz grandes desigualdades à escala mundial e mesmo dentro de determinadas sociedades. Na linha daquilo que tem sido referido, o acesso às novas tecnologias da saúde e da informação e comunicação permanecem escassos em grupos sociais determinados.

A tecnologia não se expressa unicamente como um artefato possibilitador de novos tipos de funcionalidades, mas sim como uma ideologia que enquadra a sua utilização, uma visão instrumental que molda o mundo e a relação com os demais seres.

A UNESCO se manifestou no sentido de proteger o genoma humano, sendo dessa forma, mais um óbice ao uso desmedido da tecnologia para a criação de um novo ser humano conforme destaca Ascensão (2008): 
Não é raro proceder-se assim. A Declaração Universal da UNESCO sobre o genoma humano e os Direitos do homem oferece-nos uma ilustração categórica. Quando os estudos sobre o genoma humano se foram desenvolvendo, a UNESCO emitiu uma Declaração solene cujo art. 1 continha esta afirmação: o genoma humano é patrimônio comum da humanidade. (ASCENSÃO, 2008, p. 279).

Um dos destaques a ser observado no desenvolvimento se estabelece no processo de mudança, ao incorporar definições como objetivos a serem alcançados e meios de alcançá-los. Nesse sentido, o uso do termo "sustainable development" como sinônimo de "economic performance" pode englobar destaques do Transumanismo, ao associar a evolução tecnológica como instrumento de melhorias individuais e coletivas, equilibrando os processos produtivos e diminuição da dissonância do tema no aspecto econômico. (ASCENSÃO, 2008).

As novas tecnologias como formas de implementar melhorias e incrementar o desempenho dos seres não podem ser indiscriminadamente utilizadas violando direitos fundamentais já consagrados. Elas devem ser objeto de regulamentação e de uso restrito sem a modificação genética dos seres. A preservação ambiental abrange, também, a perpetuação das espécies, tal como foram concebidas.

Naves e Silva (2014), abordam a questão da manipulação genética, como atividade biotecnológica que vem trazendo perspectivas positivas para a sociedade moderna, porém pode se configurar como uma ameaça para as gerações futuras:

\footnotetext{
Para análise do nível de segurança e certeza científica sobre dado conhecimento, torna-se imperioso ressaltar que se vive em uma sociedade de risco, ou seja, não há como afastar completamente os riscos biotecnológicos. Muitas vezes é impossível, inclusive, mensurar tal risco, pois sua definição não é apenas científica. É no mínimo ingênua a ideia de que cabe exclusivamente à Ciência a definição do que é risco, sua quantificação e a delimitação de quando ele ocorre. ( NAVES, SILVA, 2014, p.359)
}

O Transumanismo e o Pós-humanismo evidenciam oportunidades e benefícios para a sociedade moderna nos campos das ciências humanas, exatas, e biológicas, porém em contrapartida implicam em riscos. No caso das manipulações genéticas é imperioso promover estudos e testes, haja vista que lidam com alterações que geram riscos de potencial elevado, em que há incerteza científica quanto à sua probabilidade de ocorrência. Essas atividades se não controladas, se constituem em ameaças ao meio ambiente e às condições de vida e dignidade das gerações futuras. 
Bauman (2011), colabora com uma reflexão acerca das preocupações com a vida moderna:

\begin{abstract}
O mundo não se mostra mais dócil para amassar e moldar; em vez disso, ele parece nos ofuscar - pesado, espesso, inerte, opaco, impenetrável e inexpugnável, inflexível e insensível a qualquer de nossas intenções, resistente a nossas tentativas de torná-lo mais hospitaleiro para a coexistência humana. A face que ele nos apresenta é misteriosa e inescrutável, como o rosto dos mais experimentados jogadores de pôquer. Não parece haver alternativa alguma para este mundo. Nenhuma alternativa que nós, os jogadores, por nossos esforços deliberados, isolada, separadamente ou juntos pudéssemos pôr em seu lugar. (BAUMAN, 2011, p.116)
\end{abstract}

A evolução da humanidade vem marchando numa direção talvez não prevista. Em um sentido favorável para as condições de bem-estar dos seres humanos, prolongamento da vida, melhoria do desempenho, progresso da medicina e de outas áreas das ciências, podendo superar limitações humanas fundamentais. Por outro sentido, indesejável no ponto de vista de sustentabilidade, com efeitos climáticos, poluição, catástrofes ambientais e ainda com os riscos ainda desconhecidos e por vir. Para Maia, 2017, "Há uma série de tecnologias emergentes, ligadas às áreas da engenharia genética, nanotecnologia, inteligência artificial, biologia sintética, criónica e relações de simbiose/epigenética, que possuem um enorme potencial para modelar as capacidades humanas e para interferirem com os ecossistemas.”

Assim permanece a reflexão e discussão acerca do tema, trazendo à tona o conceito de dignidade humana e sua permanência histórica. A continuidade dos problemas sociais e ambientais em um contexto científico e filosófico, que ameaçam a sustentabilidade e a condição humana no planeta.

\title{
4. CONSIDERAÇÕES FINAIS
}

O direito ao meio ambiente sadio acarreta limitações a determinadas manifestações e searas do ordenamento jurídico, sejam elas individuais, coletivas ou intergeracionais.

Além de partir da premissa de distinção dos chamados direitos individuais e coletivos, é necessário desvincular-se de uma visão fragmentada dos direitos humanos, evitando-se a limitação e a asserção de que não existe proteção em face à evolução tecnológica da humanidade.

A contribuição do Transumanismo no campo do direito ambiental, procede, possivelmente da necessidade que o ser humano detém dos bens ambientais, como satisfação 
das diferentes formas de apropriação e uso, bem como, pela necessidade de significar os processos da vivência humana cada vez mais confrontados com os avanços tecnocientíficos.

No contexto jurídico, há que se considerar ainda que a mera disposição desses direitos ao status constitucional não garante sua eficácia, sobremaneira em tempos em que o Estado enfrenta uma relação de descrédito que, não se pode deixar sucumbir o sistema de garantias em nome de quaisquer que sejam os valores circunstanciais que pareçam prevalecer.

Analisando as disposições normativas e de institucionalização da defesa do direto ao meio ambiente, tem-se um arcabouço robusto, porém impotente se não manejado por quem efetivamente é detentor dessa garantia, por meio de uma efetiva participação social bem como por meio de seus representantes aqui entendidos também o setor econômico e o poder público.

Observa-se ser recorrente a referência da solidariedade como fundamento da preservação ambiental, o que impõe restrição de direitos atuais como medida de proteger o acesso aos bens ambientais das gerações futuras. Nessa perspectiva há que se considerar a ligação existente entre o direito intergeracional ao meio ambiente e as garantias fundamentais. Não se trata de restringir direitos fundamentais, mas modular a disposição e fruição dos bens ambientais de modo a garantir sua permanência para o futuro.

A associação da incorporação dos benefícios tecnológicos, já é uma realidade vivenciada por muitos e terá impacto também sobre as garantias fundamentais quando promover as capacidades humanas. Como uma extensão do humano, a teoria transumanista traz contribuição na medida que possibilita repensar a forma de utilização dos recursos ambientais e de que maneira a tecnologia e o desenvolvimento da ciência podem contribuir com a ideia de garantia do direito também para as gerações por vir.

As evoluções tecnológicas são importantes e necessárias para poder viabilizar a vida moderna com ações sustentáveis como redução dos gases de efeito estufa, da poluição, do desmatamento, da mitigação de riscos na mineração e demais indústrias, gestão de resíduos, envolvendo todas as áreas do conhecimento. O retrocesso nas condições de vida é impensável e, portanto, a inovação e evolução tecnológica são fundamentais.

O debate relativo à evolução tecnocientífica no tocante ao prolongamento da vida, aumento do desempenho, engenharia genética, nanotecnologia, inteligência artificial, biologia sintética, criónica , alteração de sexo, reprodução, inseminação artificial, fertilização in vitro, clonagem, uso de novas drogas, entre outras, precisa ser avaliado tendo como pilares os 
eventuais efeitos ao meio ambiente, nas desigualdades sociais, e na própria preservação do ser humano no planeta.

\section{REFERÊNCIAS}

ASCENSÃO, J. O. A dignidade da pessoa e o fundamento dos direitos humanos. Revista da Faculdade de Direito, Universidade de São Paulo, v. 103, p. 277-299, 1 jan. 2008.

BARRETO, Vicente de Paulo. A idéia de pessoa humana e os limites da Bioética. In: BARBOSA, Heloísa Helena et al (Orgs.). Novos temas de biodireito e bioética. Rio de Janeiro/São Paulo: Renovar, 2003. p. 219.

BAUMAN, Zygmunt, 1925 - A ética é possível nu mundo de consumidores? Tradução de Alexandre Werneck - Rio de Janeiro: Zahar,2011. 272p.

BRASIL. Constituição (1988). Constituição da República Federativa do Brasil - texto constitucional de 5 de outubro de 1988 - atual., até Emenda Constitucional no 67 - 36 ${ }^{\mathrm{a}}$ ed. Brasília: Câmara dos Deputados, Coordenação de Publicações, 2012.

BRITO, Franclim Jorge Sobral de. Emancipação Socioambiental: Por uma Teoria Crítica Ambiental / Franclim Jorge Sobral de Brito; Orientadora: Danielle de Andrade Moreira - Rio de Janeiro PUC, Departamento de Direito, 2016. v., 162f

CANALTECH,2015. Transumanismo e o uso da tecnologia para aprimorar a condição humana Fontes: Gledinélio Silva Santos/Revista Pandora Brasil, David Pearce/Hedweb, Humanity Plus, Paul Root Wolpe/TED, João Lourenço de Araújo Fabiano/Revista Filosofia, Popular, Telegraph, Mic, Transhumanist Party Disponível em https://canaltech.com.br/ciencia/Transumanismo-e-o-uso-da-tecnologia-para-aprimorar-acondicao-humana-49223/. Acesso em 04.julho.2021

CANOTILHO, José Joaquim Gomes. Constituição dirigente e vinculação do legislador: contributo para a compreensão das normas constitucionais programáticas. 2. ed. Coimbra: Coimbra Editora, 2001.

FERRAJOLI, Luigi. Derechos y garantías. La ley del más débil. Traducción de Perfecto Andrés Ibáñez. 5. ed. Madrid: Editorial Trotta, 2006.

FERREIRA, Keoma F. Transumanismo e suas oscilações prometeico- fáusticas: tecnoapoteose na era tecnociencia demiúrgica, 2018, p.233-284.

FIORILLO, Celso Antonio Pacheco. Curso de direito ambiental brasileiro. Imprenta: São Paulo, Saraiva jur, 2020.

MACHADO, Paulo Afonso Leme. Direito Ambiental Brasileiro. 25a. ed. São Paulo: Malheiros, 2017. 
MACHADO, Carlos Augusto Alcântara. Mandado de Injunção: um instrumento de efetividade da constituição. - $2^{\text {a }}$ ed. São Paulo: Atlas, 2004, cap. I, p. 21-45.

MAIA, João Jerônimo Machadinha. Transumanismo e Pós-humanismo - descodificação política de uma problemática contemporânea. Tese de Doutoramento em Estudos Contemporâneos Instituto de Investigação Interdisciplinar da Universidade de Coimbra outubro de 2017.

MORAIS, José Luis Bolzan de. As crises do Estado e da Constituição e a transformação espaço-temporal dos direitos humanos. 2. ed. Porto Alegre: Livraria do Advogado Editora, 2017.

NAVES, Bruno Torquato de Oliveira, SILVA Marcela Vitoriano e. Organismos Geneticamente Modificados sob a Perspectiva da Tutela das Gerações Futuras Veredas do Direito, Belo Horizonte • v.11 • n.22 • p.355-380 •Julho/Dezembro de 2014

OST, Francois. O tempo do Direito. Lisboa: Instituto Piaget, 1999, p.39-41.

PORTER, Allen. Bioethics and transhumanism. In: The Journal of Medicine and Philosophy: A Forum for Bioethics and Philosophy of Medicine. Oxford University Press, 2017. p. 237-260.

RÜDIGER, Francisco. Breve história do Pós-humanismo: Elementos de genealogia e criticismo. Revista da Associação Nacional dos Programas de Pós-Graduação em Comunicação. Compos, Abril de 2017. 17 p.

SAMPAIO, José Adércio Leite. Democracia, constituição e realidade. Belo Horizonte: Del Rey, 2001.

SAMPAIO, José Adércio Leite. Os ciclos do constitucionalismo ecológico. Revista Jurídica da FA7, v. 13, n. 2, p. 83-101, jul./dez. 2016.

SARLET. Ingo Wolfgrang. FENSTERSEIRFER. Tiago. Direito Ambiental Constitucional. $3^{\mathrm{a}}$ edição. Revista dos Tribunais. 2013.

SILVA. José Afonso da. Direito Ambiental Constitucional. São Paulo: Malheiros, São Paulo -SP- 1994.

TOMÉ, Romeu. O princípio da vedação de retrocesso ambiental no contexto da sociedade de risco. Salvador: Jus Podivm, 2014. 